University of South Carolina

Scholar Commons

7-1993

\title{
Electronegativity and Bond Type 2. Evaluation of Electronegativity Scales
}

Gordon Sproul

University of South Carolina - Beaufort, gdsproul@uscb.edu

Follow this and additional works at: https://scholarcommons.sc.edu/beaufort_naturalsciences_facpub

Part of the Physical Chemistry Commons

\section{Publication Info}

Published in The Journal of Physical Chemistry, Volume 98, Issue 27, 1993, pages 6699-6703.

Sproul, G.D. (1994). Electronegativity and bond type 2: evaluation of electronegativity scale. Journal of Physical Chemistry, 98(27), 6699-6703. http://doi.org/10.1021/j100078a009

Copyright @ 1994, American Chemical Society

This Article is brought to you by the Department of Natural Sciences at Scholar Commons. It has been accepted for inclusion in Faculty Publications by an authorized administrator of Scholar Commons. For more information, please contact digres@mailbox.sc.edu. 


\title{
Electronegativity and Bond Type. 2. Evaluation of Electronegativity Scales
}

\author{
Gordon Sproul \\ Department of Chemistry, University of South Carolina at Beaufort, Beaufort, South Carolina 29902
}

Received: January 21, 1994; In Final Form: April 6, 1994

\begin{abstract}
Scales of electronegativity, $\chi$, can be evaluated against an empirical relationship between bond character and $\chi$. A data set of binary compounds whose bond types were specified as metallic, covalent, or ionic was used to evaluate 15 scales. For each scale, plots of differences in $\chi, \Delta \chi$, vs average $\chi, \bar{\chi}$ were made for all compounds of specified bond type. These 2-D plots produce triangular graphs that exhibit tripartite separation of the three bond types which show increasing covalency along one axis and increasing ionicity along the other axis. All but one scale produce graphs that give segregation of compounds by metallic, covalent, and ionic bond type of better than $87 \%$ for all comopunds with $\chi$ 's defined by that scale. Two scales, those of Allen and of Nagle, provide better than $96 \%$ separation into the three bond type regions.
\end{abstract}

The intuitive concept of electronegativity provides chemists with explanations for a wide range of bonding characteristics. Since its initial mathematical description, ${ }^{1}$ numerous investigators have provided improved or alternative scales that all generally agree in their relative ordering of the elements. ${ }^{2}$ However, despite considerable efforts expended to establish a clear definition and a commonly acceptable scale, there has been no agreement on which scale provides the best description of electronegativity.

Various procedures attempting to evaluate electronegativity scales have been used. One of these has been the comparison of values predicted by the scales against observable quantities, such as dipole polarizability, 3,4 ionization potential and electron affinity, ${ }^{3-5}$ or the work function. ${ }^{6}$ All of these observables (or closely related quantities) are also used in the definitions of various electronegativity scales and therefore cannot serve to independently evaluate these scales. Another commonly applied procedure has been to plot values of electronegativity from a scale to be tested against an accepted scale; ${ }^{7-11}$ agreement presumably implies verification of the validity of the scale in question. This is a specious evaluation; while it provides comparison against scales of known chemical merit, it assumes validity of the accepted standard scale without independent verification.

The purpose of this paper is to offer an alternative and independent method for evaluating the consistency and validity of scales of electronegativity based on the bond character of a large number of compounds and on an empirical relationship between bond character and electronegativity. It is expected that each of the most useful scales will have a single algorithm that consistently determines electronegativity values for those elements of chemical interest.

Interatomic bonding in solids can be divided into three basic types: metallic, covalent, and ionic. This tripolar nature of chemical bonding was first qualitatively depicted by Van Arkel ${ }^{12}$ and by Ketelaar ${ }^{13}$ in the 1940s, was incorporated by Jolly in $1976,{ }^{14}$ and has been used in a general chemistry text. ${ }^{15}$ It has been more recently plotted quantitatively using two functions of electronegativity. ${ }^{16-18}$ Using the bonding character of several hundred binary compounds, it was shown graphically in a previous paper by this author ${ }^{18}$ that these compounds fall neatly into three partitioned regions. This tripartite separation was about $95 \%$ accurate when differences in electronegativity vs average electronegativity were plotted for a particular electronegativity scale.

While it is clearly recognized that bond character is rarely of purely one type, it is also recognized that one of the three bond types typically dominates bonding in a given compound. It is

- Abstract published in Advance ACS Abstracts, June 1, 1994. hypothesized here that such tripartite separation is a general characteristic of other electronegativity scales: binary compounds of a known bond type will fall into segregated regions characteristic of their bond type when a plot is made of two independent functions of electronegativity; this will be called the separation postulate. It is further proposed that this separation can be used to evaluate various electronegativity scales.

\section{Data Selection}

A data set of binary compounds whose bond types were specified as metallic, covalent, or ionic was gleaned from Wells' Structural Inorganic Chemistry, 5th ed. ${ }^{19}$ The compounds were selected according to the following criteria: (1) all binary compounds (in order to limit analysis to a two-dimensional graph) of representative elements and zinc subfamily elements were considered (since many tables of electronegativities are limited to these), (2) gases were excluded wherever it could be determined that they were the sole source of bonding information (since gaseous molecules always have directed bonding), (3) compounds that contained elements with more than one oxidation state (e.g., $\mathrm{GaCl}_{2}$ is $\left.\mathrm{Ga}^{+}\left(\mathrm{GaCl}_{4}{ }^{-}\right)\right)$and "solid" solutions were eliminated, (4) compounds were eliminated if their bond type was ambiguous or questionable, and (5) those called "semimetallic" were not used. Exclusion of such compounds of mixed or ambiguous bonding character should make differentiation between different bond types more obvious. Bonding was considered specified and welldefined when Wells clearly indicated descriptions that conventionally are associated with specific bond types. Metallic bonding was indicated by such terms as "metal", "metallic", or "alloy"; covalent bonding was indicated by terms like "molecule(s)", "molecular structure", "covalent", "polymer", "ring(s)", and "chain(s)". Ionic bonding was indicated by terms such as "ionic", "ion(s)", or "salt-like". The 311 compounds of specified bond type are listed in the Appendix. Wells avoided any use of electronegativity when specifying bond types ${ }^{20}$ but used measurable physical and chemical parameters such as structural geometry, bond lengths, radii (van der Waals, covalent, and ionic), interatomic distances, melting and boiling points, conductivity and resistance, and stability of the compounds in water. Thus, bond type has been assigned independently of electronegativity considerations.

Although there is general relative agreement among scales, ${ }^{2}$ there are significant differences that should appear if the separation postulate can be used to evaluate different electronegativity scales. Scales were selected to evaluate against the separation postulate, including 14 that use no electronegativity 


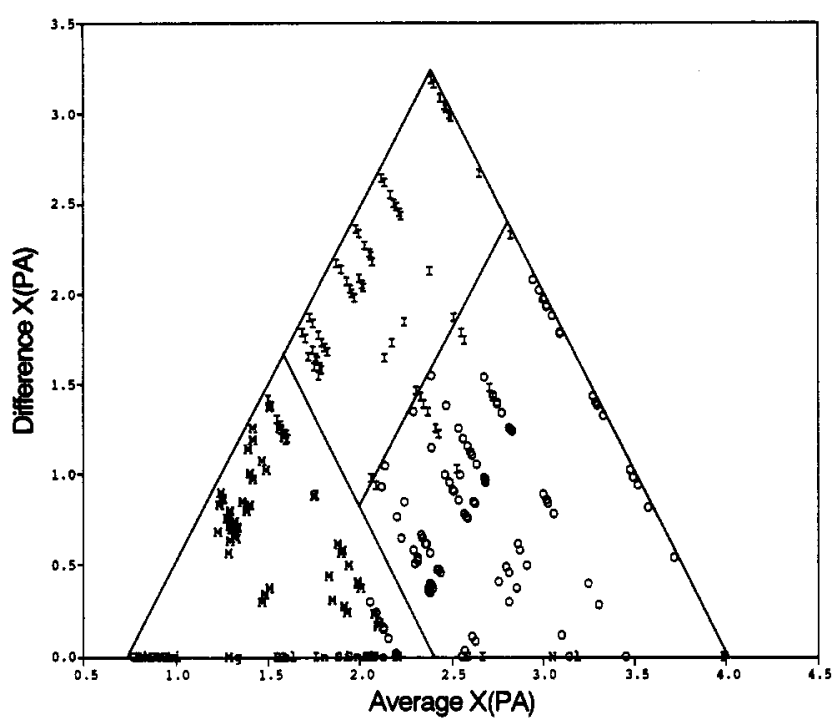

Figure 1. Graph of $\Delta x(P A)$ vs $\bar{\chi}(P A)$. $M, O$, and I are metals, covalent molecules, and ionic compounds, respectively.

equalization ${ }^{21}$ and one that uses it. These scales were chosen to give a representative variety of the diverse definitions for scales of electronegativity. Selected scales have complete or relatively complete tabulations of electronegativity values for the representative elements as well as the zinc subfamily of elements.

Fifteen electronegativity scales were chosen for evaluation. Scales based on a measured variable (indicated parenthetically) include $\chi(\mathrm{PA})$ values of Pauling and updated by Allred ${ }^{22}$ (bond energies), $\chi(\mathrm{Mk})$ of Mulliken ${ }^{23,8}$ using typical single-bonded valence states for all atoms (ionization potential and electron affinity), $\chi(\mathrm{MP})$ of values for ground-state atoms of Mulliken ${ }^{23}$ as updated using recent experimental results (ionization potential and electron affinity), ${ }^{24} \chi(\mathrm{G} 2)$ of Gordy ${ }^{11}$ (atomic covalent radius), $\chi(A R)$ of Allred and Rochow (covalent radius and effective nuclear charge), $\chi(\mathrm{Sn})$ of Sanderson ${ }^{25}$ (atomic radius and effective nuclear charge), $\chi(\mathrm{MB})$ of Martynov and Batsanov ${ }^{10}$ (valence electron energy), $\chi(\mathrm{Al})$ of Allen ${ }^{26,27}$ (valence shell spectroscopic energies), and $\chi(\mathrm{Ng})$ of $\mathrm{Nagle}^{28}$ (static electric dipole polarizability). Scales that are determined theoretically from energy functions include those based on the Mulliken ${ }^{23}$ definition, developed by Hinze, Whitehead, and Jaffe; 29 these include $\chi(\mathbf{M y})$ of Mullay ${ }^{7}$ (using unhybridized orbitals except for $\mathrm{C}$ for which $\mathrm{sp}^{3}$ hybridization was assumed) and $\chi(\mathrm{BH})$ of Bratsch" using his "typical" single-bonded valence states for all atoms, using electronegativity equalization, and using the formalism of Huheey ${ }^{30}$ (energy defined by a quadratic function of charge). Electronegativity scales based on density functional methods have included $\chi(\mathrm{RB})$ of Robles and Bartolotti ${ }^{5}$ and $\chi$ (BS) of Böhm and Schmidt.,4 Composite definitions of electronegativity include $\chi(\mathrm{GT})$ of Gordy and Thomas ${ }^{6}$ and $\chi(\mathrm{Bt})$ of Batsanov. ${ }^{31}$

\section{Results}

For each electronegativity scale, plots of differences in electronegativity, $\Delta x$, vs average electronegativity, $\bar{\chi}$, were made for all compounds of specified bond type. These graphs produced isosceles triangles. The only exception was for the scale using $\chi(\mathrm{BH})$ values which employs a slightly different algorithm necessitated by equalization of electronegativity; ${ }^{21}$ this change in the graphing algorithm alters the nature of this graph but nevertheless enables qualitative comparisons to be made with the other plots. The "best" lines for separating bond types were chosen to maximize segregation of bond type; although this was a strictly empirical procedure, the separation lines were typically both obvious and unique. Examples of three representative graphs are given: Figure 1 shows the isosceles triangular plot for the

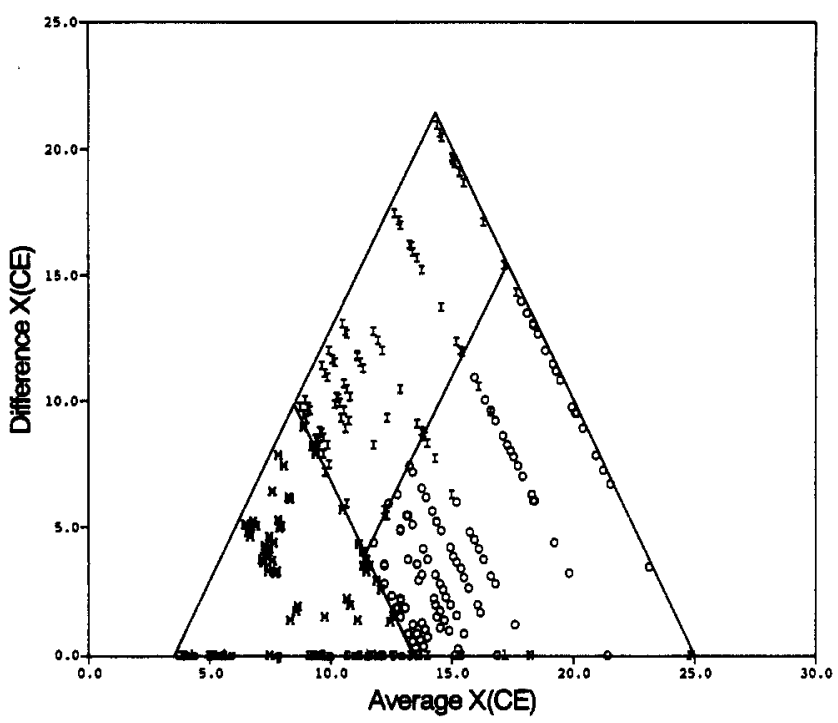

Figure 2. Graph of $\Delta \chi(\mathrm{Al})$ vs $\bar{\chi}(\mathrm{Al}) . \mathrm{M}, \mathrm{O}$, and I are metals, covalent molecules, and ionic compounds, respectively.

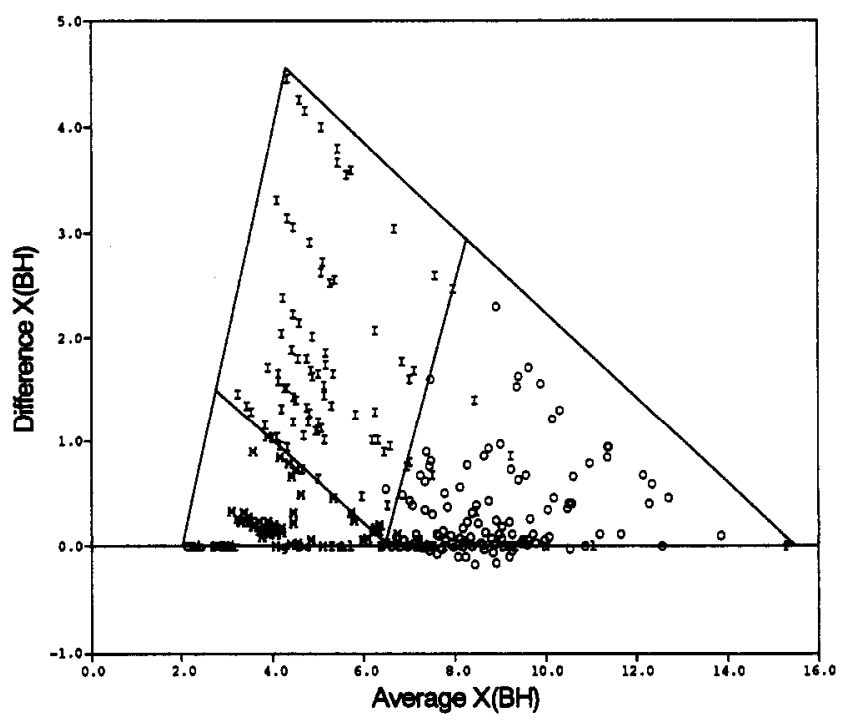

Figure 3. Graph of $\Delta \bar{\chi}(\mathrm{BH})$ vs $\bar{\chi}(\mathrm{BH})$. M, O, and I are metals, covalent molecules, and ionic compounds, respectively.

classical Pauling scale using $\chi(\mathrm{PA})$, Figure 2 shows an isosceles plot using $\chi(\mathrm{Al})$ data which gives the best segregation, and Figure 3 shows the skewed triangle when $\chi(\mathrm{BH})$ is plotted using complete hybridization equalization. Two lines were drawn on each triangle to separate regions of different bond types. These lines of separation lie parallel to the two sides of their triangle: the one lying parallel to the right side separates metallic from ionic and covalent regions and will be called the $\mathrm{M}-\mathrm{IC}$ line; the line lying parallel to the left side of the triangle separates ionic from covalently bound compounds and will be called the C-I line. These lines of separation successfully segregate most of the 311 compounds into appropriate regions for all electronegativity scales. Of the 15 scales tested, all or all but one of the covalent compounds (of a total of 163) were correctly segregated by M-IC and C-I for eight of the electronegativity scales. All or all but one of the ionic compounds (of a total of 93) were properly separated by M-IC for nine scales. And all metallic compounds (of a total of 53) were properly segregated by M-IC and C-I for eight of the scales. Analytical functions of these lines of separation are given in Table 1 for each of the scales.

Ten or more compounds lay outside "expected" bond type regions for each of the scales considered. A few of these compounds usually appear misplaced from their appropriate bond type region. Of these: 
TABLE 1: Equations of Lines for Separation of Bond Types

\begin{tabular}{|c|c|c|c|}
\hline & \multicolumn{2}{|c|}{$\chi$} & \multirow[b]{2}{*}{ units } \\
\hline & M-IC line & C-I line & \\
\hline $\begin{array}{l}\chi(\mathrm{Al}) \\
\chi(\mathrm{Ng}) \\
\chi(\mathrm{MB}) \\
\chi(\mathrm{MP}) \\
\chi(\mathrm{AR}) \\
\chi(\mathrm{Sn}) \\
\chi(\mathrm{Mk}) \\
\chi(\mathrm{PA}) \\
\chi(\mathrm{G} 2) \\
\chi(\mathrm{BH}) \\
\chi(\mathrm{My}) \\
\chi(\mathrm{RB}) \\
\chi(\mathrm{BS}) \\
\chi(\mathrm{Bt}) \\
\chi(\mathrm{GT})\end{array}$ & $\begin{array}{l}-1 / 2 \Delta x+13.47 \\
-1 / 2 \Delta x+2.25 \\
-1 / 2 \Delta x+2.35 \\
-1 / 2 \Delta x+5.75 \\
-1 / 2 \Delta x+2.15 \\
-1 / 2 \Delta x+2.55 \\
-1 / 2 \Delta x+7.6 \\
-1 / 2 \Delta x+2.30 \\
-1 / 2 \Delta x+2.3 \\
-1 / 4 \Delta x+6.4 \\
-1 / 2 \Delta x+2.05 \\
-1 / 2 \Delta x+5.6 \\
-1 / 2 \Delta x+8.5 \\
-1 / 2 \Delta x+2.1 \\
-1 / 2 \Delta x+2.3\end{array}$ & $\begin{array}{l}1 / 2 \Delta x+9.46 \\
1 / 2 \Delta x+1.50 \\
1 / 2 \Delta x+1.42 \\
1 / 2 \Delta x+4.0 \\
1 / 2 \Delta x+1.4 \\
1 / 2 \Delta x+1.5 \\
1 / 2 \Delta x+5.3 \\
1 / 2 \Delta x+1.59 \\
1 / 2 \Delta x+1.3 \\
1 / 2 \Delta x+6.4 \\
1 / 2 \Delta x+1.45 \\
1 / 2 \Delta x+4.2 \\
1 / 2 \Delta x+5.0 \\
1 / 2 \Delta x+1.25 \\
1 / 2 \Delta x+1.3\end{array}$ & $\begin{array}{l}\mathrm{eV} \\
\text { (none) } \\
\text { ( } \sqrt{ } \text { energy) } \\
\mathrm{eV} \\
\text { (force) } \\
\text { (none) } \\
\mathrm{eV} \\
\text { ( } \sqrt{ } \text { energy) } \\
\text { (potential) } \\
\mathrm{eV} \\
\text { ( } \sqrt{ } \text { energy) } \\
\mathrm{eV} \\
\mathrm{eV} \\
\text { (none) } \\
\text { (none) }\end{array}$ \\
\hline
\end{tabular}

(i) Three are specified as ionic but always appear (for all 15 scales) within the covalent region; these are $\mathrm{Ge}_{3} \mathrm{~N}_{4}, \mathrm{GeO}_{2}$, and $\mathrm{SnO}_{2}$.

(ii) Additionally, several other compounds nearly always fall in regions designated for a different bond type. With the exception of $\chi(\mathrm{BH})$, which "correctly" locates the compound in the ionic region, all other scales locate $\mathrm{Ca}_{2} \mathrm{P}_{2}$ in the metallic region. Similarly, several compounds specified as ionic are located in the covalent region; with the exceptions of the electronegativity scales noted which properly place them, the compounds that are misplaced in this fashion are $\mathrm{Al}_{4} \mathrm{C}_{3}$ except by $\chi(\mathrm{MP}), \chi(\mathrm{BH})$, and $\chi(\mathrm{RB})$ which place it within the correct bond region; $\mathrm{HgF}_{2}$ except by $\chi(\mathrm{G} 2)$ and $\chi(\mathrm{RB})$ which properly place it; and AlN, $\mathrm{GaN}$, and InN except by $\chi(\mathrm{MP})$ and $\chi(\mathrm{RB})$ which correctly locate them.

(iii) Also, there are many compounds whose locations usually differ from those specified by their bond type. These included $\mathrm{AsH}_{3}, \mathrm{~B}_{2} \mathrm{H}_{6}, \mathrm{~B}_{4} \mathrm{H}_{10}, \mathrm{~B}_{6} \mathrm{H}_{10}, \mathrm{GeH}_{4}, \mathrm{Ge}_{2} \mathrm{H}_{6}, \mathrm{Ge}_{3} \mathrm{H}_{8}, \mathrm{PH}_{3}, \mathrm{SbH}_{3}$, $\mathrm{SiH}_{4}, \mathrm{Si}_{5} \mathrm{H}_{10}$, and $\mathrm{SnH}_{4}$, which are specified as covalent but appear in the metallic region in all scales except for $\chi(\mathrm{Al}), \chi(\mathrm{MP}), \chi-$ (BH), $\chi(\mathrm{Ng})$, and $\chi(\mathrm{Sn})$ in which they fall in the proper region. Others are $\mathrm{BaH}_{2}, \mathrm{CaH}_{2}, \mathrm{CsH}, \mathrm{KH}, \mathrm{LiH}, \mathrm{MgH}_{2}, \mathrm{NaH}, \mathrm{RbH}$, and $\mathrm{SrH}_{2}$, which are specified as ionic but fall in the metallic region in all electronegativity scales except for $\chi(\mathrm{Al}), \chi(\mathrm{MP}), \chi(\mathrm{BH})$, $\chi(\mathrm{Ng})$, and $\chi(\mathrm{Sn})$, where they are properly defined. Finally, other compounds that were designated as ionic but usually fall within the covalent region are $\mathrm{ZnF}_{2}, \mathrm{Zn}_{3} \mathrm{~N}_{2}, \mathrm{ZnO}$, and $\mathrm{ZnO}_{2}$, except for $\chi(\mathrm{Al}), \chi(\mathrm{Bt}), \chi(\mathrm{G} 2), \chi(\mathrm{BH})$, and $\chi(\mathrm{Ng})$ which correctly locate them.

Quality of separation for each scale of electronegativity was evaluated; both the number of compounds with at least one undefined electronegativity value and the number of compounds which fell outside the specified bond type region were used. Various ratios were then calculated to evaluate correlation between the separation postulate and the agreement found with each scale. A weighting function that would indicate separation distance from the "correct" bond type region was considered but rejected because of the subjectiveness in selecting a weighting scheme. Agreement fractions were determined using ratios that indicate fractional deviation from the separation postulate. These were calculated for the electronegativity scales using four terms: total number, 311, which was the entire number of specified compounds; number misplaced, which is the number of compounds that appeared in a region different from their specified bond type; number undefined, which is the number of compounds that are not defined by the particular scale; and number plotted, which includes only those compounds that had defined electronegativities for both elements and so was total number minus number undefined. The agreement fractions used are

$$
\begin{aligned}
& a=1-[(\text { number misplaced }) /(\text { number plotted })] \\
& b=1-[\text { (number misplaced }) /(\text { total number })]
\end{aligned}
$$

$c=1-[(($ number misplaced + number undefined $) /$

(total number))]

The closer each value is to one, the better the scale agrees with the separation postulate; perfect agreement would be 1.00. These agreement fractions are tabulated in Table 2.

\section{Discussion}

All atomic as well as ortibal electronegativity scales evaluated, no matter the algorithm used for their definition, produce twodimensional graphs that effectively divide bonding of binary compounds into three nearly exclusive regions: metallic, covalent, and ionic. When $\Delta \chi$ is plotted against $\bar{\chi}$, bond character appears not only as the historically recognized tripolar distribution around the metallic, covalent, and ionic vertices of a triangular graph but also within well-divided tripartite regions. The obvious separation provides nearly complete segregation for the vast majority of compounds. This strongly indicates the validity of the separation postulate and its ability to successfully classify bond character of binary compounds. While few if any compounds are bound by purely covalent, ionic, or metallic bonds, preselection of compounds with clearly describable primary bonding character produces relatively obvious separation. Compounds with highly mixed bonding character would be expected to fall near lines of separation. Such mixed bonding creates some ambiguity in the precise location of lines of separation and therefore in the agreement fractions. However, since the data show such obvious separation, this is not expected to significantly modify these findings.

Two-dimensional plots of $\Delta \chi$ vs $\bar{\chi}$ produce graphs showing fractional bonding contributions arising from covalency along one axis and from ionicity along the other axis. Nearly every binary compound exhibits this fractional bond type along these two continua. The first of these ranges from metallic bonding (delocalized sea of electrons) to covalent bonding (localized shared electrons) with increasing localization of the electrons between two bonded atoms. The second continuum extends from equally shared electrons (homoatomic metallic and covalent bonding) to transferred electrons (ionic bonding between strongly heteroatomic atoms) with increasing ionic character. The continuum from shared to transferred electrons has been generally designated by difference in electronegativity values. While this difference alone has sometimes been used to describe ionic character, it has never been satisfactory. ${ }^{32,33}$ However, by separating the electronegativity of bonded atoms into two independent functions, the separate contributions to bonding character can be recognized. Contributions of $\bar{\chi}$ along the metallic-to-covalent continuum can be identified with the covalent character of bonding electrons. Contributions of $\Delta x$ along the shared-to-transferred continuum can be labeled the ionic character of a bond. Thus, the separation postulate makes intuitive chemical sense. It is seen that, in general, the further a given compound appears from the metallic apex of the triangle, the stronger the interatomic bond.

\begin{tabular}{|c|c|c|c|c|c|c|c|c|c|c|c|c|c|c|c|}
\hline & $\chi(\mathrm{Al})$ & $\chi(\mathrm{Ng})$ & $\chi(\mathrm{MB})$ & $\chi(\mathrm{MP})$ & $x(\mathrm{AR})$ & $\chi(\mathbf{S n})$ & $x(\mathbf{M k})$ & $\chi(\mathbf{P A})$ & $x(\mathrm{G} 2)$ & $\chi(\mathrm{BH})$ & $\chi(\mathrm{My})$ & $\chi(\mathrm{RB})$ & $\chi(B S)$ & $\chi(B t)$ & $x(G T)$ \\
\hline $\begin{array}{l}a \\
b\end{array}$ & $\begin{array}{l}0.97 \\
0.97 \\
0.97\end{array}$ & $\begin{array}{l}0.96 \\
0.96 \\
0.96\end{array}$ & $\begin{array}{l}0.94 \\
0.95 \\
0.82\end{array}$ & $\begin{array}{l}0.93 \\
0.93 \\
0.92\end{array}$ & $\begin{array}{l}0.92 \\
0.93 \\
0.81\end{array}$ & $\begin{array}{l}0.93 \\
0.93 \\
0.93\end{array}$ & $\begin{array}{l}0.90 \\
0.90 \\
0.90\end{array}$ & & & & $\begin{array}{l}0.93 \\
0.95 \\
0.68\end{array}$ & & & $\begin{array}{l}0.95 \\
0.96 \\
0.82\end{array}$ & $\begin{array}{l}0.87 \\
0.87 \\
0.86\end{array}$ \\
\hline
\end{tabular}

TABLE 2: Agreement Fractions 
In order to use the separation postulate to evaluate various electronegativity scales, the accuracy of specification of bond type must be considered. That there are a number of compounds misplaced by all or most of the electronegativity scales provokes some concern. This misplacement can arise from various causes:

(i) Misplacement could be caused by inaccurate values of electronegativity due to selection of improper observable quantities or theoretical models in defining specific electronegativity scales. Since different scales of electronegativity provide different values, it is certain that some are less accurate and will provide weaker predictive value than others. This, of course, is the reason for attempting evaluation of these several scales. Improper assignment appears very likely for several scales, particularly for those with numerous misplaced hydrides, for which the electronegativity assignment for hydrogen seems too low. These include scales of $\chi(\mathrm{G} 2), \chi(\mathrm{Mk}), \chi(\mathrm{PA}), \chi(\mathrm{GT})$, and $\chi(\mathrm{BS})$.

(ii) Misplacement could arise from improper assignment of bond type by Wells. Since bond character is rarely of a single pure type, most compounds exhibit a mixture of bond types. This blending of bond character is clearly seen in the graphs and those misplaced compounds that are typically found near boundaries. Such inaccurate specification appears likely for most if not all of the nine compounds described above as always or almost always found to be misplaced from the expected region. Efforts toward clarifying bond character in misplaced compounds are proceeding.

It is expected that the better a given scale conforms to the separation postulate, the better the scale will be in its capacity for predicting other chemical properties. In order to compare the 15 electronegativity scales, agreement fractions were calculated for comparison. These were found to fall into four categories (of which one has two subcategories). Scales with excellent agreement with $a, b$, and $c$ all greater than 0.96 were $\chi(\mathrm{Al})$ and $\chi(\mathrm{Ng})$. Scales with good agreement with $a$ and $b$ as well as with $c$ all greater than 0.92 but less than 0.96 were $\chi(\mathrm{BH}), \chi(\mathrm{MP})$, $\chi(\mathrm{RB})$, and $\chi(\mathrm{Sn})$; those with $a$ and $b$ greater than 0.92 but less than 0.96 but with $c$ between 0.68 and 0.82 (due to a significant number of undefined elements) were $\chi(\mathrm{Bt}), \chi(\mathrm{MB}), \chi(\mathrm{AR})$, and $\chi(\mathrm{My})$. Scales in fair agreement with $a, b$, and $c$ all greater than 0.86 but less than 0.92 were $\chi(\mathrm{Mk}), \chi(\mathrm{PA}), \chi(\mathrm{GT})$, and $\chi(\mathrm{G} 2)$. And the scale in poor agreement with $a, b$ and $c$ all less than 0.83 was $\chi(B S)$. These are shown in Table 2.

An adequate electronegativity scale should have defined values for at least all important elements. Since hydrogen is found in more compounds than any other element, it is essential to have a value for this element. However, the scales for $\chi(\mathrm{AR}), \chi(\mathrm{Bt})$, and $\chi(\mathrm{MB})$ do not have values for this element determined by the defining algorithm.

A theoretically valid scale should be defined by a single consistent algorithm. However, the scales of $\chi(\mathrm{Bt})$ and $\chi(\mathrm{GT})$ are composite definitions and do not meet this criterion.

Two electronegativity scales, $\chi(\mathrm{Al})$ and $\chi(\mathrm{Ng})$, show the greatest ability to separate binary compounds into appropriate bond regions; these two have a predictive capability of better than $96 \%$. Additionally, both of these scales provide electronegativity values for all elements evaluated. Finally, both scales are defined by single consistent algorithms. Therefore, misplacement of compounds by these two scales should be particularly useful in evaluating specifications of bond type. Indeed, of the 10 misplaced compounds in the $\chi(\mathrm{Al})$ scale, all are also misplaced in most other scales; in the $\chi(\mathrm{Ng})$ scale all but three of the 12 misplaced compounds are also misplaced in most other scales. (The three exceptions are misplaced in five or six of the other scales.) This fact again emphasizes the likelihood of incorrect bond type specification for a few of the compounds, while confirming correct bond type specification for the great majority of compounds. This excellent agreement shows the ability of certain electronegativity scales to predict not only the nature of bond character between atoms in binary compounds but also the ability of these scales to indicate probable errors in identification of marginal bond types.

It has long been recognized that an electronegativity difference of greater than 1.7 in Pauling electronegativity units corresponds to compounds that are primarily ionic. ${ }^{34}$ Similarly, if metallic compounds are ignored, values less than 1.7 generally correspond to covalent compounds. Figure 1 clarifies why this single function $\Delta \chi$ has served with some success in separating ionic from covalent compounds. If the two-dimensional triangle is reduced to a onedimensional line along $\Delta x$, nearly all compounds above 1.7 , and certainly above 2.1, are ionic. Again, neglecting metallic compounds, it is clear that most compounds are found to be covalent when $\Delta \chi$ is less than about 1.7 and certainly covalent when it is less than 0.9. At the same time this figure depicts why this single function has proven unsatisfactory in several ways: (i) It implies that a single term, $\Delta \chi$, is sufficient to separate ionic from covalent bonding; proper separation is shown to require two terms. (ii) It implies that $\Delta x$ can provide a (perhaps fuzzy) point separating ionic from covalent bonding; in fact, this value is seen to range from 0.9 to 2.1. (iii) It ignores metallic bonding; in fact, metallic bonding is shown to be an integral part of the bonding continuum.

\section{Conclusion}

All 15 electronegativity scales considered give graphs of differences in electronegativity $v s$ average electronegativity that effectively segregate binary compounds into three regions of metallic, covalent, or ionic bond type for the 311 compounds considered. It is shown that two parameters are necesary to satisfactorily segregate compounds into their appropriate bond types. This separation provides a comparison of the extent of covalent character in a bond with the contribution from ionic character. At the same time these graphs indicate the relative proportions of the three "pure" bond types that occur in bonds of binary compounds. While graphical analysis shows that, for all scales, two lines separate regions of different bond character, two of these scales give a separation that is significantly better than others. All but one of the scales produce graphs that give separation of better than $87 \%$ for all compounds with electronegativities defined by that scale. Two scales, those of Allen and of Nagle, provide better than $96 \%$ segregation into the three bond type regions for all 311 compounds.

Note Added in Proof. An article describing the geometrical and chemical relationships of a modern version of the Van-ArkelKetelaar Triangles has recently been published. ${ }^{34}$ Using $\chi(\mathrm{Al})$, families of binary compounds of the representative elements are subdivided by bonding types into metallic, covalent, and ionic subregions.

Acknowledgment. I thank Prof. Jerry Odom for valuable suggestions and encouragement. This work was supported by University of South Carolina's Research and Productive Scholarship Fund.

\section{Appendix. Bond Types for Binary Compounds, As Specified by Wells ${ }^{19}$}

Covalent Compounds. $\mathrm{AlBr}_{3}, \mathrm{AlCl}_{3}, \mathrm{AlI}_{3}, \mathrm{AsBr}_{3}, \mathrm{AsCl}_{3}, \mathrm{AsH}_{3}$, $\mathrm{AsI}_{3}, \mathrm{As}_{2} \mathrm{O}_{3}, \mathrm{As}_{2} \mathrm{~S}_{3}, \mathrm{As}_{4} \mathrm{~S}_{3}, \mathrm{As}_{4} \mathrm{~S}_{4}, \mathrm{As}_{4} \mathrm{~S}_{5}, \mathrm{As}_{4} \mathrm{Se}_{3}, \mathrm{BBr}_{3}, \mathrm{~B}_{9} \mathrm{Br}$, $\mathrm{B}_{4} \mathrm{C}, \mathrm{B}_{2} \mathrm{Cl}_{4}, \mathrm{~B}_{4} \mathrm{Cl}_{4}, \mathrm{~B}_{8} \mathrm{Cl}_{8}, \mathrm{~B}_{9} \mathrm{Cl}_{9}, \mathrm{BF}_{3}, \mathrm{~B}_{2} \mathrm{H}_{6}, \mathrm{~B}_{4} \mathrm{H}_{10}, \mathrm{~B}_{6} \mathrm{H}_{10}, \mathrm{BI}_{3}$, $\mathrm{BN}, \mathrm{BO}_{3}, \mathrm{~B}_{2} \mathrm{O}_{3}, \mathrm{~B}_{2} \mathrm{~S}_{2}, \mathrm{~B}_{2} \mathrm{~S}_{3}, \mathrm{~B}_{3} \mathrm{~S}_{3}, \mathrm{~B}_{16} \mathrm{~S}_{16}, \mathrm{BrF}_{5}, \mathrm{CBr}_{4}, \mathrm{CCl}_{4}, \mathrm{C}_{2}-$ $\mathrm{Cl}_{6}, \mathrm{CF}_{4}, \mathrm{CH}_{4}, \mathrm{C}_{2} \mathrm{H}_{2}, \mathrm{C}_{2} \mathrm{H}_{4}, \mathrm{C}_{2} \mathrm{H}_{6}, \mathrm{C}_{2} \mathrm{I}_{4}, \mathrm{C}_{2} \mathrm{~N}_{2}, \mathrm{CO}_{2}, \mathrm{CS}_{2}, \mathrm{CSi}$, $\mathrm{ClF}, \mathrm{ClF}_{3}, \mathrm{ClO}_{2}, \mathrm{GaBr}_{3}, \mathrm{GaI}_{3}, \mathrm{GaS}, \mathrm{GeF}_{2}, \mathrm{GeH}_{4}, \mathrm{Ge}_{2} \mathrm{H}_{6}, \mathrm{Ge}_{3} \mathrm{H}_{8}$, $\mathrm{GeI}_{4}, \mathrm{HBr}, \mathrm{HCl}, \mathrm{HF}, \mathrm{HI}, \mathrm{H}_{2} \mathrm{O}, \mathrm{H}_{2} \mathrm{O}_{2}, \mathrm{H}_{2} \mathrm{~S}, \mathrm{HgBr}_{2}, \mathrm{Hg}_{2} \mathrm{Br}_{2}$, $\mathrm{HgCl}_{2}, \mathrm{Hg}_{2} \mathrm{Cl}_{2}, \mathrm{HgI}_{2}, \mathrm{Hg}_{2} \mathrm{I}_{2}, \mathrm{HgO}, \mathrm{HgS}, \mathrm{IBr}, \mathrm{ICl}_{2} \mathrm{I}_{2} \mathrm{Cl}_{6}, \mathrm{IF}_{5}, \mathrm{IF}_{7}$, $\mathrm{I}_{2} \mathrm{O}_{5}, \mathrm{InCl}_{3}, \mathrm{KrF}_{2}, \mathrm{NCl}_{3}, \mathrm{~N}_{2} \mathrm{~F}_{2}, \mathrm{~N}_{2} \mathrm{~F}_{4}, \mathrm{NH}_{3}, \mathrm{~N}_{2} \mathrm{H}_{2}, \mathrm{~N}_{2} \mathrm{H}_{4}, \mathrm{NI}_{3}$, $\mathrm{NO}, \mathrm{N}_{2} \mathrm{O}, \mathrm{N}_{2} \mathrm{O}_{4}, \mathrm{NP}, \mathrm{N}_{2} \mathrm{~S}_{2}, \mathrm{~N}_{3} \mathrm{~S}_{3}, \mathrm{~N}_{4} \mathrm{~S}_{4}, \mathrm{~N}_{6} \mathrm{~S}_{5}, \mathrm{~N}_{4} \mathrm{Se}_{4}, \mathrm{OF}_{2}, \mathrm{O}_{2} \mathrm{~F}_{2}$, $\mathrm{PBr}_{3}, \mathrm{PBr}_{5}, \mathrm{PBr}_{7}, \mathrm{PCl}_{3}, \mathrm{PF}_{3}, \mathrm{P}_{2} \mathrm{~F}_{4}, \mathrm{PH}_{3}, \mathrm{PI}_{3}, \mathrm{PN}, \mathrm{P}_{3} \mathrm{~N}_{5}, \mathrm{P}_{4} \mathrm{O}_{7}$, 
$\mathrm{P}_{4} \mathrm{O}_{8}, \mathrm{P}_{4} \mathrm{O}_{9}, \mathrm{P}_{4} \mathrm{O}_{10}, \mathrm{P}_{4} \mathrm{~S}_{3}, \mathrm{P}_{4} \mathrm{~S}_{5}, \mathrm{P}_{4} \mathrm{~S}_{7}, \mathrm{P}_{4} \mathrm{~S}_{9}, \mathrm{P}_{4} \mathrm{~S}_{10}, \mathrm{P}_{4} \mathrm{Se}_{3}, \mathrm{~S}_{2} \mathrm{Cl}_{2}$ $\mathrm{SF}_{4}, \mathrm{SF}_{6}, \mathrm{~S}_{2} \mathrm{I}_{2}, \mathrm{SO}_{2}, \mathrm{SO}_{3}, \mathrm{SbBr}_{3}, \mathrm{SbCl}_{3}, \mathrm{SbCl}_{5}, \mathrm{SbF}_{3}, \mathrm{SbH}_{3}, \mathrm{SbI}_{3}$, $\mathrm{Sb}_{2} \mathrm{O}_{3}, \mathrm{Sb}_{4} \mathrm{O}_{6}, \mathrm{Sb}_{2} \mathrm{~S}_{3}, \mathrm{SeBr}_{4}, \mathrm{SeCl}_{4}, \mathrm{SeH}_{2}, \mathrm{SeO}_{2}, \mathrm{SeO}_{3}, \mathrm{Se}_{3} \mathrm{~S}_{5}$, $\mathrm{Se}_{4} \mathrm{~S}_{4}, \mathrm{Si}_{6} \mathrm{Cl}_{16}, \mathrm{SiF}_{4}, \mathrm{Si}_{2} \mathrm{~F}_{6}, \mathrm{SiH}_{4}, \mathrm{Si}_{5} \mathrm{H}_{10}, \mathrm{SiO}_{2}, \mathrm{SnBr}, \mathrm{SnBr}_{4}$ $\mathrm{SnCl}_{2}, \mathrm{SnCl}_{4}, \mathrm{SnF}_{2}, \mathrm{SnF}_{4}, \mathrm{SnH}_{4}, \mathrm{TeBr}_{4}, \mathrm{TeCl}_{4}, \mathrm{TeF}_{4}, \mathrm{TeH}_{2}, \mathrm{TeI}$, $\mathrm{TeI}_{4}, \mathrm{TeO}_{2}, \mathrm{XeF}_{2}, \mathrm{XeF}_{4}, \mathrm{XeO}_{3}, \mathrm{ZnS}$.

Ionic Compounds. $\mathrm{Al}_{4} \mathrm{C}_{3}, \mathrm{AlN}, \mathrm{BaBr}_{2}, \mathrm{BaC}_{2}, \mathrm{BaCl}_{2}, \mathrm{BaF}_{2}$, $\mathrm{BaH}_{2}, \mathrm{BaI}, \mathrm{BaO}, \mathrm{BaO}_{2}, \mathrm{BaS}, \mathrm{Be}_{2} \mathrm{C}, \mathrm{Be}_{3} \mathrm{~N}_{2}, \mathrm{BeO}, \mathrm{C}_{2} \mathrm{Ca}, \mathrm{CaF}_{2}$, $\mathrm{CaH}_{2}, \mathrm{Ca}_{2} \mathrm{~N}, \mathrm{Ca}_{3} \mathrm{~N}_{2}, \mathrm{CaO}, \mathrm{CaO}_{2}, \mathrm{Ca}_{2} \mathrm{P}_{2}, \mathrm{CaS}, \mathrm{Cd}_{3} \mathrm{~N}_{2}, \mathrm{CdO}_{2}$, $\mathrm{CsBr}, \mathrm{CsCl}, \mathrm{CsF}, \mathrm{CsH}, \mathrm{CsI}, \mathrm{CsO}_{2}, \mathrm{Cs}_{2} \mathrm{O}, \mathrm{Cs}_{2} \mathrm{O}_{2}, \mathrm{Cs}_{2} \mathrm{~S}, \mathrm{GaN}$, $\mathrm{Ge}_{3} \mathrm{~N}_{4}, \mathrm{GeO}_{2}, \mathrm{HgF}_{2}$, InN, $\mathrm{KBr}, \mathrm{KCl}, \mathrm{KF}, \mathrm{KH}, \mathrm{KI}, \mathrm{KO}_{2}, \mathrm{~K}_{2} \mathrm{O}$, $\mathrm{K}_{2} \mathrm{O}_{2}, \mathrm{~K} 2 \mathrm{~S}, \mathrm{LiBr}, \mathrm{LiCl}, \mathrm{LiF}, \mathrm{LiH}, \mathrm{LiI}, \mathrm{Li}_{3} \mathrm{~N}, \mathrm{Li}_{2} \mathrm{O}, \mathrm{Li}_{2} \mathrm{O}_{2}, \mathrm{Li}_{2} \mathrm{~S}$, $\mathrm{MgBr}_{2}, \mathrm{MgCl}_{2}, \mathrm{MgF}_{2}, \mathrm{MgH}_{2}, \mathrm{Mg}_{3} \mathrm{~N}_{2}, \mathrm{MgO}, \mathrm{NaBr}, \mathrm{NaCl}, \mathrm{NaF}$, $\mathrm{NaH}, \mathrm{NaI}, \mathrm{Na}_{2} \mathrm{O}, \mathrm{Na}_{2} \mathrm{O}_{2}, \mathrm{Na}_{2} \mathrm{~S}, \mathrm{RbBr}, \mathrm{RbCl}, \mathrm{RbF}, \mathrm{RbH}, \mathrm{RbI}$, $\mathrm{RbO}_{2}, \mathrm{Rb}_{2} \mathrm{O}, \mathrm{Rb}_{2} \mathrm{~S}, \mathrm{SnO}_{2}, \mathrm{SrBr}_{2}, \mathrm{SrC}_{2}, \mathrm{SrCl}_{2}, \mathrm{SrF}_{2}, \mathrm{SrH}_{2}, \mathrm{SrI}_{2}$, $\mathrm{Sr}_{3} \mathrm{~N}_{2}, \mathrm{SrO}, \mathrm{SrO}_{2}, \mathrm{SrS}, \mathrm{ZnF}_{2}, \mathrm{Zn}_{3} \mathrm{~N}_{2}, \mathrm{ZnO}, \mathrm{ZnO}_{2}$.

Metallic Compounds. AlAs, AlLi, $\mathrm{Al}_{3} \mathrm{Mg}_{2}, \mathrm{Al}_{30} \mathrm{Mg}_{23}$, AlP, AlSb, $\mathrm{BaSi}_{2}, \mathrm{BaZn}_{5}, \mathrm{Be}_{13} \mathrm{Ba}, \mathrm{Be}_{13} \mathrm{Ca}, \mathrm{Be}_{3} \mathrm{P}_{2}, \mathrm{Cd}_{11} \mathrm{Ba}, \mathrm{Cd}_{13} \mathrm{Cs}$, $\mathrm{CdHg}, \mathrm{Cd}_{13} \mathrm{~K}, \mathrm{CdLi}, \mathrm{CdMg}_{3}, \mathrm{Cd}_{3} \mathrm{Mg}, \mathrm{Cd}_{3} \mathrm{P}_{2}, \mathrm{Cd}_{13} \mathrm{Rb}, \mathrm{Cd}_{11} \mathrm{Sr}$, $\mathrm{Cs}_{3} \mathrm{Sb}, \mathrm{GaLi}, \mathrm{GaP}, \mathrm{GaSb}, \mathrm{GeAs}, \mathrm{GeP}, \mathrm{HgLi}, \mathrm{HgNa}, \mathrm{Hg}_{2} \mathrm{Na}$, $\mathrm{Hg}_{2} \mathrm{Na}_{3}$, InAs, InLi, InNa, InP, InSb, KGe, $\mathrm{K}_{3} \mathrm{P}, \mathrm{KSn}, \mathrm{Li}_{3} \mathrm{P}$, $\mathrm{LiZn}, \mathrm{Mg}_{3} \mathrm{P}_{2}, \mathrm{MgZn}_{2}, \mathrm{NaIn}, \mathrm{Na}_{3} \mathrm{P}, \mathrm{NaSi}, \mathrm{SnP}, \mathrm{SrZn_{5 }}, \mathrm{Zn}_{13} \mathrm{Ba}$, $\mathrm{Zn}_{13} \mathrm{Ca}, \mathrm{Zn}_{13} \mathrm{~K}, \mathrm{Zn}_{13} \mathrm{Na}, \mathrm{Zn}_{13} \mathrm{Rb}, \mathrm{Zn}_{13} \mathrm{Sr}$.

\section{References and Notes}

(1) Pauling, L. Yost, D. M. Proc. Natl Acad. Sci. U.S.A. 1932, 18,414 (2) Mullay, J. In Structure and Bonding, Sen, K. D., Jørgensen, C. K., Eds.; Springer-Verlag: New York, 1987; Vol. 66, pp 1-25.

(3) Bohm, M. C.; Schmidt, P. C. Ber. Bunsen-Ges. Phys. Chem. 1986, 90, 913-919.

(4) Sen, K. D.; Bőhm, M. C.; Schmidt, P. C. In Structure and Bonding; Sen, K. D., Jørgensen, C. K., Eds.; Springer-Verlag: New York, 1987; Vol. 66, pp 99-123.

(5) Robles, J.; Bartolotti, L. J. J. Am. Chem. Soc. 1984, 106, 3723-3727.

(6) Gordy, W.; Thomas, W. J. O. J. Chem. Phys. 1956, 24, 439-444.

(7) Mullay, J. J. Am. Chem. Soc. 1984, 106, 5842-5847.
(8) Bratsch, S. G. J. Chem. Educ. 1988, 65, 34-41.

(9) Allred, A. L.; Rochow, E. G. J. Inorg. Nucl. Chem. 1958, 5, 264-268. (10) Martynov, A. I.; Batsanov, S. S. Russ. J. Inorg. Chem. 1980, 25 , 1737-1739.

(11) Gordy, W. Phys. Rev. 1946, 69, 604-607.

(12) Van Arkel, A. E. Molecules and Crystals; Interscience: London, 1949; p 205.

(13) Ketelaar, J. A. A. Chemical Constitution-An Introduction to the Theory of the Chemical Bond; Elsevier: New York, 1953; p 21.

(14) Jolly, W. L. The Principles of Inorganic Chemistry; McGraw-Hill Book Co.: New York, 1976.

(15) Moeller, T.; Bailer, J. C., Jr.; Kleinberg, J.; Castellion, M. E.; Metz, C. Chemistry with Inorganic Analysis; Academic Press: New York, 1980; p 259.

(16) Jensen, W. B. Electronic Equivalency and the Periodic Table; University of Cincinnati: 1991, Lecture. Presented at Symposium on Chemical Bonding, University of Wisconsin, Madison, July 1980 (unpublished).

(17) Allen, L. C. J. Am. Chem. Soc. 1992, 114, 1510-1511.

(18) Sproul, G. D. J. Chem. Educ. 1993, 70, 531-534

(19) Wells, A. F. Structural Inorganic Chemistry, 5th ed.; Clarendon Press: Oxford, 1984.

(20) Wells, A. F. Reference 19, pp 289-290

(21) Sanderson, R. T. Science 1951, 114, 670-672.

(22) Allred, A. L. J. Inorg. Nucl. Chem. 1961, 17, 215-221.

(23) Mulliken, R. S. J. Chem. Phys. 1934, 2, 782-793.

(24) Parr, R. G.; Yang, W. Density Functional Theory of Atoms and Molecules; Oxford University Press: New York, 1989.

(25) Sanderson, R. T. Simple Inorganic Substances; R. E. Krieger: Malabar, FL, 1989.

(26) Allen, L. C. J. Am. Chem. Soc. 1989, 111, 9003-9014.

(27) Allen, L. C.; Knight, E. T. J. Mol. Struct. (THEOCHEM) 1991, $261,313-330$.

(28) Nagle, J. K. J. Am. Chem. Soc. 1990, 112, 4741-4747.

(29) Hinze, J.; Whitehead, M. A.; Jaffe, H. H. J. Am. Chem. Soc. 1963, $85,148-154$

(30) Huheey, J. E. Inorganic Chemistry, 3rd ed.; Harper and Row: New York, 1983; pp 149-160.

(31) Batsanov, S. S. Russ. Chem. Rev. 1982, 51, 684-697.

(32) Pauling, L. The Nature of the Chemical Bond; Cornell University Press: Ithaca, NY, 1960, pp 97-101.

(33) Holzclaw, H. F., Jr.; Robinson, W. R.;Odom, J.D. Gernal Chemistry with Qualitative Analysis, 9th ed. D.C. Heath: Lexington, MS, 1991; 186.

(34) Allen, L. C.; Capitani, J. F.; Kolks, G. A.; Sproul, G. D. J. Mol. Struct. 1993, 300, 647-655. 